\title{
Role of Biological Response Modifiers in the Treatment of Rheumatoid Arthritis-A Review
}

\author{
Md. Azizul Haque ${ }^{1}$, A R M Saifuddin Ekram², Quazi Tarikul Islam³
}

\begin{abstract}
Rheumatoid arthritis is a chronic disease with the potential to cause substantial joint damage and disability. ${ }^{1}$ During the past 10 years, improved understanding of the pathophysiology of rheumatoid arthritis has led to several key changes in the approach to therapy. Most important of that is the development of some biological agents interfering with the activity of several important cytokines. Infliximab, etanarcept, and adalimumab are TNF blockers, anakinra is IL-1 receptor antagonist, and rituximab is anti CD-20 monoclonal antibody. These newer agents proved to be useful for alleviating symptoms and slowing the disease progression in the patients with RA who have failed to respond to conventional DMARDs.
\end{abstract}

TAJ 2005; 18(1): 60-65

\section{Introduction}

Rheumatoid arthritis (RA) is a chronic, autoimmune, inflammatory systemic disease of unknown etiology characterized by persistent joint inflammation that results in progressive joint destruction, joint deformity, and physical disability. It affects $1 \%$ of the world population. ${ }^{1}$ When the disease is unchecked, it leads to substantial disability and premature death. The average life expectancy of RA patients is decreased by 3 to 18 years compared to age and gender matched controls ${ }^{1}$. Recent advances in understanding the cytokine networks that are responsible for the ongoing inflammatory response in rheumatoid arthritis ${ }^{2}$ have led to the successful use of therapies that target tumor necrosis factor $\alpha$ $(\mathrm{TNF}-\mathrm{e})$ and interleukin-1 and other molecular mediators ${ }^{3}$.

During the past 10 years, improved understanding of the pathophysiology of rheumatoid arthritis has led to several key changes in the approach to therapy. First, early diagnosis and treatment are important. Second, the use of disease-modifying antirheumatic drugs (DMARDs) in combination is highly effective. Third, the use of agents that target cytokines, such as TNF- $\alpha$ and interleukin-1, is an effective strategy. And fourth, recognition is growing that the assessment of treatment outcomes should include an analysis of important coexisting illnesses (particularly cardiovascular disease and osteoporosis). In this article, I will discuss the clinical application of these principles, which has resulted in a marked improvement in clinical outcome. $^{4}$

\section{Role of cytokines in the pathogenesis of RA}

While a $\mathrm{T}$ cell mediated, antigen-specific process is undoubtedly critical to the initiation of RA, sustained inflammation is at least equally dependent on cytokine production by synovial macrophages and fibroblasts which may act on

\footnotetext{
${ }^{1}$ Resident physician, Rajshahi Medical College Hospital, Rajshahi-6000

2 Professor of Medicine, Rajshahi Medical College, Rajshahi-6000

${ }^{3}$ Associate Professor of Medicine, Rajshahi Medical College, Rajshahi-6000
} 
each other in an autocrine or paracrine manner. Tumor necrosis factor- $\alpha$ (TNF- $\alpha$ ) and interleukin-1 (IL-1) are the major macrophagederived cytokines present in the rheumatoid joint and both induce the synthesis and secretion from synovial fibroblasts of matrix-degrading proteases, prostanoids, interleukin-6 (IL-6), interleukin-8 (IL-8) and granulocyte-macrophage colony stimulating factor (GM-CSF). As well as activating endothelial cells and thereby promoting adhesion of neutrophils, it had been observed that TNF-alpha shared with interleukin-1 (IL-1) the property of stimulating resorption of cartilage and inhibiting synthesis of proteoglycan. Patients with rheumatoid arthritis have high concentrations of TNF- $\alpha$ in the synovial fluid. ${ }^{5}$ Consequently, attention has focused on inhibition of TNF-alpha as a way to treat RA.TNF is produced primarily by macrophages and, to a lesser extent, by lymphocytes. In contrast to the relatively restricted synthesis of TNF-a by macrophages and $\mathrm{T}$ cells, TNF receptors (TNF-R) are expressed by nearly every mammalian cell. There are two types of TNF receptors, designated as TNF-RI (or p55) and TNF-RII (or p75). ${ }^{2}$ IL-1 is a cytokine that has immune and pro-inflammatory actions and has the ability to regulate its own expression by autoinduction. Evidence supports the fact that the level of disease activity in RA, and progression of joint destruction, correlates with plasma and synovial fluid levels of $\mathrm{IL}-1^{2}$. There are two specific immunoglobulin-like membrane bound IL-1 receptors (IL-1R), types I and II, found in both humans and animals. Among these two interleukin receptors only IL-1 receptor type 1 is functionally active. A complete biological response requires only $1 \%$ to $2 \%$ occupancy of IL1 type I receptors on a target cell ${ }^{5}$.

\section{Development of TNF inhibitors}

The two strategies for inhibiting TNF that have been most extensively studied to date consist of monoclonal anti-TNF antibodies and soluble TNF receptors (sTNF-R). Both constructs will theoretically bind to circulating TNF- $\alpha$, thus limiting its ability to engage cell membrane-bound TNF receptors and activate inflammatory pathways.
The best studied of the monoclonal anti-TNF antibodies is infliximab originally referred to as cA2. Infliximab is a chimeric human/mouse monoclonal anti-TNF alpha antibody composed of the constant regions of human IgG, coupled to the high-affinity neutralizing murine anti-Human TNF alpha antibody. The antibody exhibits high affinity for recombinant and natural human TNF alpha, and neutralizes TNF-mediated cytotoxicity and other functions in vitro. ${ }^{6}$ Because of the potential for an immune reaction to the mouse protein components of a chimeric antibody, an alternate strategy has been to develop a fully human anti-TNF monoclonal antibody. One such antibody, known as D2E7, also known as adalimumab, was generated by phage display technology.

In the second approach to TNF inhibition, soluble TNF-receptors have been engineered as fusion proteins in which the extracellular ligand-binding portion of the human TNF-RI or human TNF-RII is coupled to a human immunoglobulin-like molecule. Although TNF-RI is thought to mediate most of the biological effects of TNF in vivo, engineered sTNF-RI and sTNF-RII constructs both appear to be effective in vivo inhibitors of TNF. Etanercept is the best studied of the sTNF-R and is approved for the treatment of rheumatoid arthritis in adults and in children. It is a dimeric construct in which two sTNF-RII (p75) are linked to the Fc portion of human IgG1.Pegylated soluble TNF receptor 1 , which has a prolonged half life, is under development ${ }^{23}$ (Table 1).

Table I: TNF Inhibitors Currently Approved or in Development

\begin{tabular}{lll}
\hline \multicolumn{1}{c}{ Name } & \multicolumn{1}{c}{ Description } & \multicolumn{1}{c}{ Status } \\
\hline Infliximab & $\begin{array}{l}\text { Mouse-human chimeric } \\
\text { anti-hu TNF } \\
\text { monoclonal Ab }\end{array}$ & FDA approved \\
Adalimumab & $\begin{array}{l}\text { Fully human anti-hu } \\
\text { TNF monoclonal Ab } \\
\text { p75 sTNF-RII-FC }\end{array}$ & FDA approved \\
Etanercept & $\begin{array}{l}\text { FDA approved } \\
\text { (dimeric) }\end{array}$ & In development \\
(None) & $\begin{array}{l}\text { PEG-p55 sTNF-RI } \\
\text { (monomeric) }\end{array}$ & Development \\
Lenercept & $\begin{array}{l}\text { p55 sTNF-RI-IgG1 } \\
\text { (dimeric) }\end{array}$ & \begin{tabular}{l} 
terminated \\
\hline
\end{tabular} \\
\hline
\end{tabular}




\section{Clinical trials with TNF inhibitors}

Because the safety of the TNF inhibitors in humans was unknown, early trials in RA targeted patients with severe, longstanding disease that had failed to respond adequately to conventional treatments such as methotrexate, gold salts, immunosuppressives and others. More recently, as the safety of these agents unfolded, patients with juvenile RA and adults with early RA have been targeted.

Both the short-term efficacy and the toxic effects of new drugs for rheumatoid arthritis are usually evaluated in clinical trials of 6 to 12 months' duration. Improvement is most often defined by an outcome measure of the American College of Rheumatology (ACR) called the ACR 20. ${ }^{9}$ The ACR 20 is defined as a reduction by 20 percent or more in the number of tender and swollen joints plus similar improvement in at least three of the following five measures: pain, global assessments by the patient and the physician, self-assessed physical disability, and levels of acute-phase reactant. Two other outcome measures that are deemed to be more clinically relevant, the ACR 50 (improvement of 50 percent or more) and the ACR 70 (improvement of 70 percent or more), are also often reported. However, the "gold standard" for evaluating the efficacy of a treatment in rheumatoid arthritis is its ability to slow or halt radiographic progression of the disease - that is, the treatment must slow or halt the development of new or enlarging erosions and slow the development of new or progressive joint space narrowing.

Both infliximab and etanercept have been studied extensively in human subjects, and both are now FDA approved for the treatment of RA. Initially, because of the experimental nature of these treatments, only patients with long-standing, severe RA were evaluated and the identified outcome was clinical (but not radiologic) improvement. Although many of these patients had failed multiple conventional treatments for RA (such as methotrexate, gold, etc.), clinical responses to the TNF inhibitors were gratifyingly robust and rapid. More recently, patients with early disease have been targeted for study and their responses have been similarly robust. Even more compelling are radiographic data in both early and late disease patients which demonstrate the ability of anti-TNF agents to slow or halt radiographic damage in the majority of patients. These data provide "proof of concept" in humans that TNF is indeed an important pathogenic mediator of joint damage in RA. Perhaps most intriguing about these studies is that targeting (inhibiting) a single cytokine can profoundly alter the natural history of this disease.

Infliximab is usually given in a dose of $3 \mathrm{mg} / \mathrm{kg}$ as an IV infusion at ' 0 ', '2', '6' weeks repeated every two months thereafter. It has a half-life of 8-12 days. A single infusion of infliximab (1 or $10 \mathrm{mg}$ per kilogram) was reported to improve symptoms of rheumatoid arthritis rapidly, providing early evidence of the effectiveness of TNF antagonism. ${ }^{9}$ Subsequent studies demonstrated that monotherapy with infliximab (at a dose of 3 or $10 \mathrm{mg}$ per kilogram) was superior to placebo, ${ }^{10}$ but the frequent development of anti-infliximab antibodies led to its use in combination with methotrexate rather than as monotherapy. Four regimens infliximab at a dose of 3 or $10 \mathrm{mg}$ per kilogram every four or eight weeks combined with methotrexate-were all similarly and significantly more effective than methotrexate plus placebo. After 54 weeks, the ACR 20 response rate ranged from 42 percent (with $3 \mathrm{mg}$ per kilogram every 8 weeks) to 59 percent (with $10 \mathrm{mg}$ per kilogram every 4 weeks). ${ }^{11}$ All regimens of infliximab plus methotrexate were more effective than methotrexate plus placebo in preventing progression as measured radiologically. ${ }^{11}$ Patients who do not have an adequate response or who have an initial response followed by a relapse may have a better response either if the interval between infusions is decreased to every four to six weeks or if the dose is increased. ${ }^{12}$

In the Anti TNF Research Study Programme of the Monoclonal Antibody Adalimumab in RA (ARMADA) 15 trial 271 patients with active RA 
on concurrent methotrexate were randomized to Adalimumab (in doses of 20,40, or $80 \mathrm{mg}$ subcutaneously every other week) or placebo. At 24 weeks more patients in the Adalimumab group met ACR 20 response criteria than in placebo group (47.8\%, 65.7\%, 65.8\% Vs $14.5 \%$; $\mathrm{P}<0.001$ for each comparison). ${ }^{25}$

In a randomized, double-blind study, the ACR 20 response rate for $40 \mathrm{mg}$ of adalimumab administered subcutaneously weekly was similar to the rate for the same dose administered every other week (53 percent and 46 percent, respectively), and both were significantly higher than the rate with placebo (19 percent $)^{13}$. Adalimumab appears to have additive effects when used with methotrexate. ${ }^{14}$

Etanercept is given as a $25 \mathrm{mg}$ subcutaneous (sc) injection twice a week. It has a half life of 4-5 days. In TEMPO trial (Trial of Etanercept and Methotrexate with radiographic Patient Outcomes) combination therapy of etanercept with methotrexate significantly slowed progression of structural damage as assessed by radiography. ${ }^{25}$ After dose-finding studies, a $10-\mathrm{mg}$ dose of etanercept, a 25-mg dose of etanercept, and placebo were compared in 234 patients in a six-month randomized study. ${ }^{15}$ Both doses of etanercept appeared to be effective, resulting in ACR 20 response rates of 51 percent and 59 percent, respectively, as compared with 11 percent in the placebo group. The 25-mg dose resulted in a more rapid response and more frequent ACR 50 responses (40 percent) than the $10-\mathrm{mg}$ dose (24 percent) or placebo (5 percent). Another study indicated that patients with an inadequate response to methotrexate receive benefit when etanercept is added to their regimen rather than placebo.${ }^{16}$

\section{Potential side effects of TNF blockers}

TNF plays an important role in host defenses, particularly in the killing of intracellular microorganisms such as Listeria and mycobacteria, aspergillosis, histoplasmosis and in inducing apoptosis of some tumor cells. Consequently, there has been some concern that long-term inhibition of TNF could lead to an increased incidence of infection and of malignancy (especially lymphoma). In addition, as these agents are genetically engineered proteins that will be given repeatedly over long periods, issues of immunogenicity with formation of antibodies against these drugs, require scrutiny. Injection site reactions like minor redness, itching, urticaria and very rarely anaphylaxis can also occur. Thirteen percent patients treated with infliximab developed human anti chimeric antibodies thereby increasing the potential for future infusion reactions. Drug induced lupus erythematosus occurred in less than $0.5 \%$ of patients treated with infliximab. ${ }^{17}$

\section{Precautions while using TNF alpha blockers}

Anti-TNF therapy should not be started in patients with active infection and should be discontinued if a serious infection occurs. Chronic or recurrent infection is a relative contraindication. All patients should be screened for latent tuberculosis before anti-TNF therapy is begun, and should be treated before starting such therapy if they test positive. ${ }^{18}$ Physicians should be alert to the increased risk of tuberculosis and other opportunistic infections.

\section{IL-1 receptor antagonist}

Anakinra is a recombinant form of human interleukin-1-receptor antagonist that targets the type I interleukin-1 receptor that is expressed in many tissues. Anakinra, alone or in combination with methotrexate, has been more effective than placebo in randomized, controlled trials involving approximately 900 patients with rheumatoid arthritis . ${ }^{19}$ Anakinra is given subcutaneously in a dose of $1-2 \mathrm{mg} / \mathrm{kg} /$ day. A long-term extension study documented that responses seen in the first 24-week phase of the study were durable; after 48 weeks, 18 percent of patients treated with anakinra had an ACR 50 response, and 3 percent had an ACR 70 response. ${ }^{20}$ Treatment with anakinra also significantly slows the rate of damage, as measured on radiography. Anakinra may be useful in patients who have no response to or are unable to tolerate methotrexate, leflunomide, or TNF antagonists. The combination of anakinra and 
methotrexate appears to be well tolerated. However, both drugs can lower the white-cell count; thus, regular laboratory monitoring is required. Concomitant use of anakinra and a TNF antagonist may increase the risk of infections and should be avoided. ${ }^{20}$

\section{Rituximab}

Rituximab is an anti-CD 20 chimeric mouse/human monoclonal antibody approved in 1997 for the treatment of B-cell lymphomas. It is hypothesized that, rheumatoid arthritis may be driven by auto-reactive B-lymphocytes. Rituximab tends to deplete $\mathrm{B}$ cells, thus diminishing the progression of the disease. Five patients with refractory seropositive rheumatoid arthritis, who had failed five or more disease modifying drugs, were treated with a four week course of rituximab in conjunction with prednisolone $(60 \mathrm{mg}$. daily for 10 days, then $30 \mathrm{mg}$. daily for 12 days) and cyclophosphamide (750 mg. iv x2). At six months all patients achieved an ACR 50, and three achieved an ACR $70 .^{21}$

\section{Limitations and future directions}

The drugs discussed above appear to be relatively safe and effective in the short-to-intermediateterm treatment of rheumatoid arthritis. Treatments for rheumatoid arthritis continue to advance rapidly, and many new drugs are under investigation; some have shown promise in clinical trials that have been published. These include tacrolimus, an interleukin-6 antagonist, and a fusion protein - cytotoxic T-lymphocyteassociated antigen 4-IgG1 (CTLA-4-Ig) - those blocks T-cell costimulatory pathways. Other drugs that are now at earlier stages of development include pegylated, soluble TNF receptor antagonists and agents that trap cytokines, block interleukin-15, prevent the cleavage of human complement component $\mathrm{C} 5$, or inhibit adhesion molecules. The introduction of additional effective therapies for rheumatoid arthritis will improve the outlook for patients, since even with the range of therapies currently available; some patients still have poorly or incompletely controlled disease. ${ }^{22}$

\section{References}

1. Scott DL, Symmons DPM, Coulton BL, Popert AJ. Long-term outcome of treating rheumatoid arthritis: results after 20 years. Lancet 1987; 1:1108-1111.

2. Choy EHS, Panayi GS. Cytokine pathways and joint inflammation in rheumatoid arthritis. $\mathrm{N}$ Engl J Med 2001; 344:907-916

3. McInnes IB. Rheumatoid arthritis: from bench to bedside. Rheum Dis Clin North Am 2001; 27:373-387

4. Krishnan E, Fries JF. Reduction in long-term functional disability in rheumatoid arthritis from 1977 to 1998: a longitudinal study of 3035 patients. Am J Med 2003; 115:371-376

5. Le J, and Vilcek, J. Tumor necrosis factor and interleukin-1: Cytokines with multiple overlapping biological activities. Lab Invest 56:234-248, 1987

6. Eastgate JA, Symons JA, Wood NC, Grinlinton FM, di Giovine FS, Duff GW. Correlation of plasma Interleukin-1 levels with disease activity in rheumatoid arthritis. Lancet 2:706-709, 1998

7. Dower SK, Wignall J, Schooley K, McMahan CJ , Jackson J., Prickett KS, Lupton S, Cosman, D, and Sims JE. J Immunol 142:4312-4320, 1989

8. Felson DT, Anderson JJ, Boers M, et al. Preliminary definition of improvement in rheumatoid arthritis. Arthritis Rheum 1995; 38:727-735

9. Elliott $M J$, Maini RN, Feldmann $M$, Long-Fox $A$, Charles P, Katsikis P, Brennan FM, Walker J, Bijl $\mathrm{H}$, Ghrayeb J, and Woody JN. Treatment of rheumatoid arthritis with chimeric monoclonal antibodies to tumor necrosis factor alpha. Arthritis Rheum 12: 1681-1690, 1993

10. Elliott MJ, Maini RN, Feldmann M, et al. Randomised double-blind comparison of chimeric monoclonal antibody to tumour necrosis factor alpha (cA2) versus placebo in rheumatoid arthritis. Lancet 1994; 344:1105-1110

11. Maini RN, Breedveld FC, Kalden JR, et al. Therapeutic efficacy of multiple intravenous infusions of anti-tumor necrosis factor alpha monoclonal antibody combined with low-dose weekly methotrexate in rheumatoid arthritis. Arthritis Rheum 1998;41: 1552-1563

12. Lipsky PE, van der Heijde DMFM, St Clair EW, et al. Infliximab and methotrexate in the treatment of rheumatoid arthritis. N Engl J Med 2000; 343: 15941602

13. van de Putte LBA, Atkins $C$, Malaise $M$, et al. Adalimumab (D2E7) monotherapy in the treatment of patients with severely active rheumatoid arthritis. Arthritis Rheum 2002;46:Suppl:S205-S205. abstract 
14. Abbott Laboratories. Humira (adalimumab). Advisory Committee briefing document, February 4, 2003. (Accessed April 26, 2004)

15. Moreland LW, Schiff MH, Baumgartner SW, et al. Etanercept therapy in rheumatoid arthritis: a randomized, controlled trial. Ann Intern Med 1999; 130:478-486

16. Weinblatt ME, Kremer JM, Bankhurst AD, et al. A trial of etanercept, a recombinant tumor necrosis factor receptor:Fc fusion protein, in patients with rheumatoid arthritis receiving methotrexate. $\mathrm{N}$ Engl J Med 1999; 340:253-259

17. Food and Drug Administration, Center for Drug Evaluation and Research, Arthritis Advisory Committee. Safety update meeting on TNF blocking agents. Tuesday, March 4, 2003. (Accessed April 26, 2004)

18. Furst DE, Cush J, Kaufmann S, Siegel J, Kurth R. Preliminary guidelines for diagnosing and treating tuberculosis in patients with rheumatoid arthritis in immunosuppressive trials or being treated with biological agents. Ann Rheum Dis 2002; 61

19. Bresnihan B, Alvaro-Gracia JM, Cobby M, et al. Treatment of rheumatoid arthritis with recombinant human interleukin-1 receptor antagonist. Arthritis Rheum 1998; 41:2196-2204
20. Fleischmann RM, Schechtman J, Bennett R, et al. Anakinra, a recombinant human interleukin-1 receptor antagonist ( $r$-metHulL-1ra), in patients with rheumatoid arthritis: a large, international, multicenter, placebo-controlled trial. Arthritis Rheum 2003; 48:927-934

21. Edwards JC, Cambridge G, Leandro MJ. Sustained improvement in rheumatoid arthritis following $B$ lymphocyte depletion. Arthritis Rheum 43(9, Suppl): S391, 2000

22. Nancy J. Olsen, and C. Michael Stein. New Drugs for Rheumatoid Arthritis. N Engl J Med 2004; 350:2167-2179

23. Smolen JS, Steiner G. Therapeutic strategies for rheumatoid arthritis. Nat Rev Drug Discov 2003; 2:473-488

24. D Vander Heijde, L. Klareskoy J. De Jager et al. Radiographic outcomes of a double-blind study of etanercept and methotrexate, alone and combined, in patients with active rheumatoid arthritis. Arthritis Rheum.2003; 48: S 122.

25. Furst D E, Weinblatt M E, Arthur Kavanaugh et al. Improvement of the individual ACR components in ACR 20 responders in an adalimumab RA clinical trial Arthritis Rheum 2003; 48:S106.

All correspondence toMd. Azizul Haque Resident Physician Rajshahi Medical College Hospital, Rajshahi. 